\title{
Mediating effects of social support and self-concept on depressive symptoms in adults with spinal cord injury
}

\author{
C-Y Huang ${ }^{1}, \mathrm{~W}-\mathrm{K} \mathrm{Chen}^{2}, \mathrm{C}-\mathrm{Y} \mathrm{Lu}{ }^{1}, \mathrm{C}-\mathrm{C}$ Tsai ${ }^{3}, \mathrm{H}-\mathrm{L} \mathrm{Lai}{ }^{4}, \mathrm{H}-\mathrm{Y} \mathrm{Lin}{ }^{5,6}, \mathrm{~S}-\mathrm{E}$ Guo ${ }^{7}, \mathrm{~L}-\mathrm{M}$ Wu${ }^{8}$ and C-I Chen ${ }^{9}$
}

Study design: Cross-sectional, correlational design.

Objectives: To examine the effects of individual demographics, activities of daily living, social support, and self-concept on depressive symptoms in people with spinal cord injury (SCI).

Setting: A convenience sample of 135 adults with $\mathrm{SCl}$ was recruited from medical and rehabilitation centres in Taiwan.

Methods: Face-to-face, structured interviews were employed to collect information. Study questionnaires included a demographic sheet, the Barthel scale, the modified Social Support Inventory, the Huang self-concept scale and the Beck Depression Inventory. Data were analysed by structural equation modelling (SEM).

Results: The average age of the participants was 43.3 years $( \pm 11.98)$, the mean duration of injury was 114 months $( \pm 93.78)$, and most were males. Emotional support $(r=-0.173, P<0.05)$ and appraisal support $(r=-0.261, P<0.01)$ were negatively correlated with depressive symptoms. The best fitted SEM model included individual demographics and physical function, social support and selfconcept as significant predictors of depressive symptoms, with self-concept acting as a mediator in this relationship. Participants' characteristics and social support both contributed substantial indirect effects on depressive symptoms via self-concept. Self-concept also mediated the relationship between education, income, physical functioning and participants' depressive symptoms.

Conclusion: For this sample, the more negative that individuals perceived themselves, the more likely they were to report worsening depressive symptoms. The more social support that individuals have, the more likely they were to report less depressive symptoms. Further longitudinal research will help clarify the direction of these relationships.

Spinal Cord (2015) 53, 413-416; doi:10.1038/sc.2014.158; published online 30 September 2014

\section{INTRODUCTION}

Depressive symptoms are common psychological problems in people with spinal cord injury (SCI), with $\sim 20 \%$ of this population reporting significant psychological distress. ${ }^{1-5}$ Depressive symptoms, in turn, may contribute to increased hospital stays, limited physical function, and increased risk of mortality and morbidity. However, studies consistently suggest that adequate social support in addition to positive self-concept may reduce psychological distress following SCI by enhancing individuals' ability to cope with their daily lives. ${ }^{4,5}$

The definition of social support implies supportive actions, interactions and behaviours that different people provide to a person in need of support. ${ }^{6}$ The concept of social support is multidimensional, usually consisting of emotional support, informational support, tangible help, appraisal support and integration support. ${ }^{7-9}$ Emotional support is focused on the individual qualities or behaviours of supporting a person, including empathy, caring, love and trust. Informational support involves the provision of advice, suggestions and information that a person can use to address problems. Tangible help primarily comprises financial support. Appraisal support affirms one's actions or statements. Integration support refers to the provision of necessary equipment, such as a wheelchair for mobility post SCI.
Each type of social support has a unique role in supporting the needs of patients and their family caregivers.

Self-concept, or an individual's beliefs about oneself, may have a key role in the psychological adjustment process for people with SCI. ${ }^{10}$ In particular, post-traumatic stress symptoms have been noted among people with SCI who report a negative perception of themselves. ${ }^{11}$ With improved self-concept, people with SCI may cope better with their injuries. ${ }^{12}$ Proactive cognitive and behavioral coping skills may enhance self-esteem and self-efficacy for individuals with SCI. ${ }^{13,14}$

\section{Conceptual framework}

There has been an increasing amount of research investigating relationships between social support and mental health in the general population, and the findings imply that social support may act as a mediator/moderator between stress and mental health. ${ }^{15}$ Poor selfconcept is also associated with depressive symptoms, anxiety, frustration and social withdrawal. ${ }^{13,14}$ These psychosocial consequences may ultimately affect one's health and well-being. However, the effects of social support and self-concept on depressive symptoms in people with SCI are not yet clear. Self-concept has been viewed as an adjustment indicator of SCI experience; ${ }^{16}$ people with SCI demonstrate positive adjustment responses when they report high

${ }^{1}$ Department of Nursing, I-Shou University, Kaohsiung, Taiwan; ${ }^{2}$ Department of Finance, I-Shou University, Kaohsiung, Taiwan; ${ }^{3}$ Department of Nursing, MeiHo University, Pingtung, Taiwan; ${ }^{4}$ Department of Nursing, Buddhist Tzu Chi General Hospital, Hualien, Taiwan; ${ }^{5}$ Department of Nursing, I-Shou University, Kaohsiung, Taiwan; ${ }^{6}$ Department of Surgery, E-Da Hospital, Kaohsiung, Taiwan; ${ }^{7}$ Department of Nursing, Chang Gung University of Science \& Technology, Pu-tz, Chiayi, Taiwan; ${ }^{8}$ Department of Nursing, Kaohsiung Medical University, Kaohsiung, Taiwan and ${ }^{9}$ Department of Industrial Management, I-Shou University, Kaohsiung, Taiwan Correspondence: Professor C-Y Huang, Department of Nursing, I-Shou University, No.8, Yida Rd., Kaohsiung 82445, Taiwan. E-mail: chiung.huang@gmail.com

Received 23 September 2013; revised 20 August 2014; accepted 27 August 2014; published online 30 September 2014 
self-concept scores. ${ }^{17}$ The conceptual framework of this study is based on the mediating effects of social support and self-concept on depressive symptoms of people with SCI. It was hypothesised that social support and self-concept would mediate the relationship between SCI, as a health condition, and depressive symptoms. In addition, the components of self-concept were examined for further clarification. The following research questions were proposed:

1. What were the relationships between individual variables (that is, demographics, physical function, self-concept and social support) on depressive symptoms in people with SCI?

2. What were the direct/indirect relationships between participants' characteristics (that is, demographics and physical function), social support and self-concept on depressive symptoms in people with SCI?

\section{MATERIALS AND METHODS}

\section{Research design}

A cross-sectional, descriptive correlational design was employed. A convenience sample of 135 adults with an acquired spinal cord injury, the majority (96\%) having sustained a traumatic injury, was recruited from medical and rehabilitation centres in southern Taiwan. Institutional Review Board approvals were obtained for the study. Participants who met the inclusion criteria and agreed to participate were given information about the study and were free to withdraw at any time. The inclusion criteria were as follows: age of 18 years and above, documented diagnosis of a major spinal cord injury and the ability to communicate in Chinese or Taiwanese. After receiving written informed consent from participants, an investigator conducted individual face-to-face, structured interviews to collect data.

\footnotetext{
Measures

Demographic variables (age, gender, education, marital status and household income) and SCI characteristics (duration of injury and physical function) were obtained using a purposely designed information sheet. Education was categorised as illiterate, elementary, junior high, high school and college. Physical function was assessed using the Barthel scale. This is a 10-item scale with a total score between 0 and 100 that is used to measure activities of daily living, with higher scores indicating greater independence. In this study, the Cronbach's alpha for the Barthel scale was computed to be 0.91 .

Social support was measured using a modified Social Support Inventory, ${ }^{18}$ which was developed based on an existing instrument ${ }^{9}$ and the researcher's clinical expertise. The modified Social Support Inventory reflected four forms of social support: emotional support, appraisal support, informational support and tangible support. The 19-item questionnaire uses a four-point Likert scale ( $1=$ never to $4=$ always) with a total score ranging from 19 to 76 , with higher scores indicating higher levels of social support. In this study, the Cronbach's alpha for the social support scale was computed to be 0.86 .

The Huang self-concept scale was used to measure the self-concept of individuals with SCI. ${ }^{19}$ This scale consists of 29 items, ranked on a five-point scale $(1=$ strongly disagree to $5=$ strongly agree), with a higher score indicating more negative self-concept. In this study, the Cronbach's alpha for the Huang self-concept scale was 0.93 .

Depressive symptoms were assessed using the Beck Depression Inventory (BDI). The BDI is a 4-point, 21 -item scale $(0=$ rarely or none of the time to $3=$ most or all of the time), with a total score ranging from 0 to 63 ; higher scores indicate more depressive symptoms. In this study, the Cronbach's alpha for the BDI scale was computed to be 0.90 .
}

\section{Data analysis}

Data analyses proceeded in two steps, using AMOS 19.0 to conduct structural equation modelling. The first step used confirmatory factor analyses to verify the construct of self-concept and social support. Six factors (self-esteem, selfconfidence, socialisation, safety, reality and automation) were entered to verify the construct of self-concept, with one factor (reality) having a standardised factor loading of less than 0.3 . This factor was subsequently excluded from the following analyses. In turn, five self-concept factors (self-esteem, self-confidence, socialisation, safety and automation) and four dimensions of social support were used to represent the constructs of self-concept and social support, respectively. The second step involved using the hypothesised model to test whether 'social support' and 'self-concept' were mediators between individuals' characteristics and depressive symptoms. Although Garver and Mentzer $^{20}$ and Hoelter ${ }^{21}$ proposed a 'critical sample size' of 200, the generally agreed-upon value is 10 participants for every free parameter estimated. ${ }^{22}$ The current sample $(N=135)$ was suitable for a model of 13 exogenous variables.

Goodness-of-fit of the study model was mainly evaluated using the $P$-value of the variance-covariance moment, the goodness-of-fit index (GFI), the average GFI (AGFI) and the root mean square error of approximation (RMSEA). ${ }^{23-25}$ Throughout this study, a structural model was considered a good fit, if the $P$-value of the structured moment was $\geqslant 0.05$. Both the GFI and the AGFI were no less than 0.90, and the RMSEA was not higher than 0.08 . Before analysis, the data set was evaluated to meet the assumptions for outliers, normality and multicollinearity. A $P$-value $<0.05$ was set to indicate statistical significance.

\section{RESULTS}

\section{Characteristics of the sample}

Most $(83.0 \%)$ of the participants were males, and half of them $(50.3 \%)$ were married/cohabitating (see Table 1$)$. The mean depressive symptom score (from the BDI) was $13.36( \pm 11.1)$, ranged $0-46$. Approximately $35 \%$ of participants reached the criteria for depressive symptoms on the BDI; ${ }^{26} 16.3 \%$ were mild (14-19), $11.1 \%$ were moderate (20-28) and 7.4\% were severe (29-63).

\section{Relationships among variables}

Bivariate correlations revealed that those who had higher BDI scores had a newly acquired SCI $(r=-0.214)$ and were more likely to be physically dependent $(r=-0.261)$ (See Table 2$)$. The more emotional $(r=-0.173, P<0.05)$ and appraisal support $(r=-0.261, P<0.01)$ that the participants received, the fewer depressive symptoms they reported. In contrast, informational support was associated with more depressive symptoms $(r=0.558)$. Depressive symptoms positively correlated with self-concept, which suggests that participants who reported higher scores of depressive symptoms were more likely to have negative thoughts about themselves.

\section{The direct/indirect effects on depressive symptoms}

The overall goodness-of-fit statistics revealed that the employed model fit the data set well with $\mathrm{P}(\mathrm{cmin})=0.27, \chi^{2} / \mathrm{df}=1.10, \mathrm{GFI}=0.94$, $\mathrm{AGFI}=0.90$ and RMSEA $=0.03$. As shown in Figure 1 , this structural model consisted of 12 independent variables (three individuals' characteristics, four dimensions of social support and five selfconcept factors), three latent variables (individuals' characteristics, social support and self-concept) and one dependent variable (depressive symptoms). In addition, for integrated analysis concern, ordinal measurements such as education and employment were used as continuous variables. Furthermore, four dimensions of social support and five self-concept factors were arranged as mediators on depressive symptoms.

Self-concept exerted a direct effect on depressive symptoms $(\beta=0.69, P<0.001)$. Poorer self-concept contributed to a higher degree of depressive symptoms. Socio-demographic and injury characteristics had significant direct effects on depressive symptoms, that is, higher levels of education, physical independence and better income contributed to the poorer self-concept $(\beta=-0.45, P=0.003)$. Social support had significant direct effects $(\beta=-0.28, P=0.002)$ on 
Table 1 Subject characteristics $(N=135)$

\begin{tabular}{|c|c|c|}
\hline Variables & Mean (s.d.) & $\mathrm{N}(\%)$ \\
\hline Age (years) & $43.3(11.98)$ & \\
\hline Duration of injury (months) & $114.0(93.78)$ & \\
\hline \multicolumn{3}{|l|}{ Gender } \\
\hline Male & & $112(83.0)$ \\
\hline Female & & $23(17.0)$ \\
\hline \multicolumn{3}{|l|}{ Marital status } \\
\hline Single & & $45(33.3)$ \\
\hline Married/cohabitating & & $68(50.3)$ \\
\hline Widowed & & $7(5.2)$ \\
\hline Divorced (other) & & $15(11.1)$ \\
\hline \multicolumn{3}{|l|}{ School years (Education) } \\
\hline Illiterate & & $4(4.4)$ \\
\hline Elementary & & $27(20.0)$ \\
\hline Junior high & & $26(19.3)$ \\
\hline High school & & $52(38.5)$ \\
\hline College & & $24(17.7)$ \\
\hline \multicolumn{3}{|l|}{ Income (Monthly NT dollars) } \\
\hline$<20000$ & & $93(80.8)$ \\
\hline $20001-40000$ & & $17(12.5)$ \\
\hline$>40000$ & & $8(5.9)$ \\
\hline \multicolumn{3}{|l|}{ Injury area } \\
\hline Cervical & & $55(40.7)$ \\
\hline Thoracic & & $51(37.8)$ \\
\hline Lumbosacral & & $27(20)$ \\
\hline Sacral & & $2(1.5)$ \\
\hline Activities of daily living & $63.56(30.9)$ & \\
\hline $0-20$ & & $21(15.6)$ \\
\hline $21-60$ & & $31(22.5)$ \\
\hline $61-90$ & & $57(42.2)$ \\
\hline 91-99 & & $7(5.2)$ \\
\hline 100 & & $19(14.1)$ \\
\hline Depressive symptoms & $13.36(11.14)$ & \\
\hline Self-concept & $101.61(17.51)$ & \\
\hline
\end{tabular}

Household income (monthly): New Taiwan (NT) Currency. self-concept, whereby higher levels of social support led to better selfconcept.

The effects of individuals' characteristics and social support on depressive symptoms operated entirely through self-concept. This mediated relationship accounted for the non-significant direct effects of social support on depressive symptoms $(\beta=-0.03, P=0.665)$. Overall, this structural model explained $49 \%$ of the variance in selfreported depressive symptoms.

\section{DISCUSSION}

This study focuses on the relationships among demographic variables, self-concept and four dimensions of social support on depressive symptoms. The finding of a higher mean for depressive symptoms than the mean score of the general adult population is consistent with previous research studies, ${ }^{2,27}$ demonstrating that people with SCIs, long-term depressive symptoms ranged from 18 to 35\%.

This is similar to our findings, with self-concept having the most important role in people with SCI. ${ }^{28,29}$ Self-concept had the most important role in activating depressive symptoms in people with SCIs. In this study, five components of self-concept were confirmed: self-esteem, self-confidence, socialisation, safety and automation.
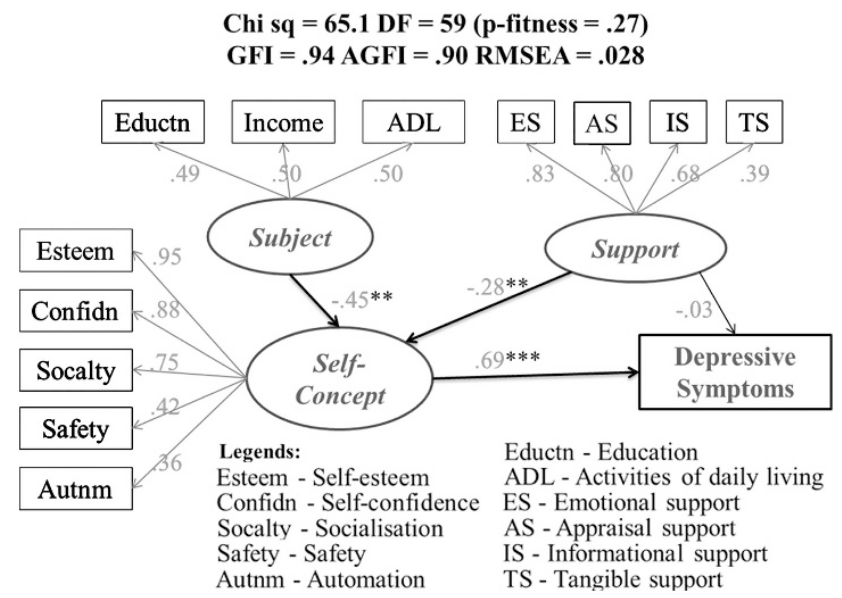

Figure 1 Model of depressive symptoms in adults with spinal cord injury. Note: ${ }^{*} P<0.01, \quad * * * P<0.001$; education and income were used as continuous variables.

Table 2 Correlations among subject characteristics, social support, self-concept and depressive symptoms

\begin{tabular}{|c|c|c|c|c|c|c|c|c|c|c|}
\hline \multicolumn{11}{|l|}{ Age } \\
\hline Education & $-0.333^{* *}$ & & & & & & & & & \\
\hline Income & $-0.193^{*}$ & $0.311^{* *}$ & 0.059 & & & & & & & \\
\hline$A D L$ & -0.115 & 0.042 & $0.189 *$ & $0.182^{*}$ & & & & & & \\
\hline ES & 0.065 & 0.105 & $-0.224^{* *}$ & 0.13 & -0.099 & & & & & \\
\hline TS & 0.098 & -0.157 & -0.047 & -0.104 & $-0.196^{*}$ & $0.440 * *$ & -0.004 & $0.395^{* *}$ & & \\
\hline DS & 0.067 & -0.079 & $-0.214^{* *}$ & -0.12 & $-0.344^{* *}$ & $-0.173^{*}$ & $0.558^{* *}$ & $-0.261^{* *}$ & 0.054 & \\
\hline SC & 0.069 & -0.11 & -0.088 & $-0.211^{*}$ & $-0.295^{* *}$ & $-0.245^{*}$ & $0.905^{* *}$ & $-0.281^{* *}$ & 0.022 & $0.644^{* *}$ \\
\hline
\end{tabular}

Abbreviations: ADL, activities of daily living; AS, appraisal support; DS, depressive symptoms; ES, emotional support; IS, informational support; SC, self-concept. Self-concept is counted in the following way: lower scores $=$ more positive thoughts. ${ }^{*} P<0.05$, ${ }^{*} P<0.01$ (Bonferroni corrections should be applied for the given number of correlations). 
This suggests that self-concept is a broad concept, and that it may be synonymous with self-esteem, acceptance, locus of control or selfefficacy.

The disability literature notes that satisfaction with both quality and quantity of social support can have an impact on psychological outcomes. ${ }^{4,30}$ Pollard and Kennedy ${ }^{27}$ reported that social support was negatively associated with depression at year 10 after an SCI event. However, contrary to the hypothesised model that both social support and self-concept were mediators between individuals' characteristics and depressive symptoms, once the effects of self-concept were taken into account, social support did not have a direct influence on depressive symptoms in the current analysis. This discrepant finding may be due to the limited definition of support examined in this study, in that only the degree of support was examined. Further research is therefore recommended to examine the effects of both the quality and quantity of social support on depressive symptoms in people with SCIs.

The results implied that self-concept was consistently associated with depressive symptoms. Health-care specialists should implement psychosocial education to enhance better self-concept in people with SCIs. Health-care professionals may coordinate support groups to achieve better self-concept of individuals with SCIs. Health-care professionals may also need to supply social access and psychological support to prompt the degree of their self-concept. According to individuals' physical condition, health-care professionals should focus on developing interventions related to coping skills, such as cognitive behaviour therapy or coping effectiveness training, to prevent people with SCI from experiencing severe depressive symptoms. ${ }^{31}$

\section{Limitations}

There are methodological and sampling limitations in this study. This study was based on a convenience sample in southern Taiwan, which might have restricted the population. The findings can only be applied to participants who have similar characteristics and backgrounds; thus, the generalisability of the results might be limited. Future research should incorporate a broader SCI sample from different locations in Taiwan. Moreover, the cross-sectional nature of the present data may make it difficult to assess study variables over time. Consequently, we could not project the longitudinal influences of independent variables such as physical function (that is, activities of daily living) or different dimensions of support on the outcomes of people with SCIs.

\section{CONCLUSION}

This study provides health-care professionals potential targets to promoting well-being in the SCI population. This includes increasing access to various forms of social support to reduce depressive symptomatology. Conversely, depressive symptoms in people with SCI may be reduced by monitoring the amount of informational support provided. Health-care professionals should design further studies to mediate and moderate the effects between different stress and health outcome variables.

\section{DATA ARCHIVING}

There were no data to deposit.

\section{CONFLICT OF INTEREST}

The authors declare no conflict of interest.
1 Elfstrom ML, Kennedy P, Lude P, Taylor N. Condition-related coping strategies in persons with spinal cord lesion: a cross-national validation of the Spinal Cord Lesionrelated Coping Strategies Questionnaire in four community samples. Spinal Cord 2007; 45: 420-428.

2 Hoffman JM, Bombardier CH, Graves DE, Kalpakjian CZ, Krause JS. A longitudinal study of depression from 1 to 5 years after spinal cord injury. Arch Phys Med Rehab 2011; 92: 411-418.

3 Saunders LL, Krause JS, Focht KL. A longitudinal study of depression in survivors of spinal cord injury. Spinal Cord 2012; 50: 72-77.

4 Muller R, Peter C, Cieza A, Geyh S. The role of social support and social skills in people with spinal cord injury - a systematic review of the literature. Spinal Cord 2012; 50: 94-106.

5 Post MW, van Leeuwen CM. Psychosocial issues in spinal cord injury: a review. Spinal Cord 2012; 50: 382-389.

6 Hupcey JE. Clarifying the social support theory-research linkage. J Adv Nurs 1998; 27: 1231-1241.

7 Krause N. Social support, stress, and well-being among older adults. J Gerontol 1986; 41: 512-519.

8 Schulz R, Rau MT. Social support through the life course. Academic Press, Inc: San Diego, CA, 1985, 129-149.

9 Barrera M, Sandler IN, Ramsy TB. Preliminary development of a scale of social support: studies on college students. Am J Community Psychol 1981; 9: 435-447.

10 Kaiser S, Kennedy P. An exploration of cognitive appraisals following spinal cord injury. Psychol Health Med 2011; 16: 708-718.

11 Hatcher MB, Whitaker C, Karl A. What predicts post-traumatic stress following spinal cord injury? Br J Health Psychol 2009; 14: 541-561.

12 Kennedy $\mathrm{P}$, Lude $\mathrm{P}$, Elfstrom ML, Smithson EF. Psychological contributions to functional independence: a longitudinal investigation of spinal cord injury rehabilitation. Arch Phys Med Rehab 2011; 92: 597-602.

13 Chen HY, Lai CH, Wu TJ. A study of factors affecting moving-forward behavior among people with spinal cord injury. Rehabil Nurs 2011; 36: 91-97 127.

14 Geyh S, Nick E, Stirnimann D, Ehrat S, Michel F, Peter C et al. Self-efficacy and selfesteem as predictors of participation in spinal cord injury-an ICF-based study. Spinal Cord 2012; 50: 699-706.

15 Huang CY, Sousa VD, Tsai CC, Hwang MY. Social support and adaptation of Taiwanese adults with mental illness. J Clin Nurs 2008; 17: 1795-1802.

16 Geyh S, Peter C, Muller R, Bickenbach JE, Kostanjsek N, Ustün BT et al. The Personal Factors of the International Classification of Functioning, Disability and Health in the literature-a systematic review and content analysis. Disabil Rehabil 2011; 33: 1089-1102.

17 Lustig DC. The adjustment process for individuals with spinal cord injury: The effect of perceived premorbid sense of coherence. Rehab Counsel Bull 2005; 48: $146-156$

18 Chang CP, Tsai YF, Chen YC, Hwang SL. Factors related to depression among burns patients. J Nurs 2001; 48: 37-48.

19 Huang YD. Body image, ego-concept, associated factors, and life adjustation in physically disability adults [Unpublished Master Thesis]. National Chengchi University: Taipei, Taiwan, 1998.

20 Garver MS, Mentzer JT. Logistics research methods: Employing structural equation modeling to test for construct validity. J Bus Logist 1999; 20: 33-57.

21 Hoelter JW. The analysis of covariance structures: Goodness-of-fit indices. Sociol Method Res 1983; 11: 325-344.

22 Hoe SL. Issues and procedures in adopting structural equation modeling techniques. $J$ Appl Quant Method 2008; 3: 76-83.

23 Jöreskog KG. A general approach to confirmatory maximum likelihood factor analysis. Psychometrika 1969; 34: 183-202.

24 Kline RB. Principles and practice of structural equation modeling, 2nd edn. Guilford Press: New York, NY, USA, 2005, xviiip. 366.

25 Steiger JH. Structural model evaluation and modification: an interval estimation approach. Multivar Behav Res 1990; 25: 173-180.

26 Beck AT, Ward $\mathrm{CH}$, Mendelson M, Mock J, Erbaugh J. An inventory for measuring depression. Arch Gen Psychiatry 1961; 4: 561-571.

27 Pollard C, Kennedy P. A longitudinal analysis of emotional impact, coping strategies and post-traumatic psychological growth following spinal cord injury: a 10-year review. Br J Health Psychol 2007; 12: 347-362.

28 Smedema SM, Catalano D, Ebener D. The relationship of coping, self-worth, and subjective well-being: a structural equation model. Rehab Counsel Bull 2010; 53: 131-142.

29 Waldron B, Benson C, O'Connell A, Byrne P, Dooley B, Burke T. Health locus of control and attributions of cause and blame in adjustment to spinal cord injury. Spinal Cord 2010; 48: 598-602.

30 van Leeuwen CM, Kraaijeveld S, Lindeman E, Post MW. Associations between psychological factors and quality of life ratings in persons with spinal cord injury: a systematic review. Spinal Cord 2012; 50: 174-187.

31 Kennedy P, Duff J, Evans M, Beedie A. Coping effectiveness training reduces depression and anxiety following traumatic spinal cord injuries. $\mathrm{Br} J$ Clin Psychol 2003; 42: 41-52. 